\title{
Food Skills and Their Relationship with Food Security and Dietary Diversity Among Asylum Seekers Living in Norway
}

\author{
Laura Terragni, $\mathrm{PhD}^{1}$; Charles D. Arnold, $\mathrm{PhD}^{2}$; Sigrun Henjum, $\mathrm{PhD}^{1}$
}

\begin{abstract}
Objective: To investigate the impact of food skills on food security and dietary diversity among asylum seekers living in Norwegian reception centers.

Design: Cross-sectional study.

Setting: Eight asylum reception centers.

Participants: A total of 205 asylum seekers (131 men and 74 women) recruited through convenience sampling.

Main Outcome Measures: Food skills were measured using questions from the Canadian Rapid Response on Food Skills and divided into cooking skills and shopping skills. Food security was measured with the 10-item version of the Radimer/Cornell Scale. The dietary diversity score was based on a 24-h recall.

Analysis: Bivariate and multivariable logistic regression.

Results: Cooking skills were associated with adequate dietary diversity (adjusted odds ratio, 2.12; 95\% confidence interval, 1.04-4.31), but not with adult food insecurity (adjusted odds ratio. 0.63; 95\% confidence interval, 0.26-1.53). Shopping skills were not associated with either measure of dietary diversity or adult food insecurity. Women had higher cooking skills than men, but there were no gender differences in shopping skills.

Conclusions and Implications: Food skills had a limited association with food security and dietary diversity. Further research is needed to identify food skills beneficial for asylum seekers and to address the multiple causes of food insecurity.
\end{abstract}

Key Words: food skills, food security, dietary diversity, asylum seekers, Norway (J Nutr Educ Behav. 2020; 52:1026-1034.)

Accepted May 25, 2020. Published online July 8, 2020.

\section{INTRODUCTION}

Food insecurity among asylum seekers and newly resettled refugees living in Western countries has been documented by several studies. ${ }^{1-4}$ Food insecurity refers to the condition in which people have limited or uncertain availability of nutritionally adequate and safe foods, or limited or uncertain ability to acquire acceptable foods in socially acceptable manners. ${ }^{5}$

Previous studies have shown that food insecurity is often not solely the result of financial constraints but of several interwoven factors related to entitlements, access to food, and the capability to prepare nutritious meals. ${ }^{6,7}$ In his studies on food security, Amartya Sen introduced the concept of food capacity, meaning

\footnotetext{
${ }^{1}$ Department of Nursing and Health Promotion, Faculty of Health Sciences, Oslo Metropoli$\tan$ University (OsloMet), Oslo, Norway

${ }^{2}$ Institute for Global Nutrition, University of California Davis, Davis, CA Conflict of Interest Disclosure: The authors have not stated any conflicts of interest.

Address for correspondence: Laura Terragni, PhD, Faculty of Health Sciences, Oslo Metropolitan University (OsloMet), P.O. Box 4. St. Olavs Plass, 0130 Oslo, Norway; E-mail:

lterragn@oslomet.no

(C) 2020 The Authors. Published by Elsevier Inc. on behalf of Society for Nutrition Education and Behavior. This is an open access article under the CC BY license. (http:// creativecommons.org/licenses/by/4.0/)

the "nutrition-related" capability of transforming food into something edible and having a healthy and varied diet. ${ }^{7-9}$

Nutrition-related capacity is increasingly recognized as an important component of food security, and there is a growing number of nutrition interventions promoting food skills among low-income populations. ${ }^{10-14}$ Food skills have been defined as the knowledge enabling the selection and preparation of nutritionally balanced, age-appropriate, and satisfying meals with available resources. ${ }^{15-18}$ Specifically, food skills include several components related to the capability of cooking, health concerns, and food safety as well as the capability of planning, budgeting, and reading labels. ${ }^{16,18}$

Studies evaluating the impact of food skills on food security have provided contrasting results. Although 
there is evidence that increased food skills can contribute to better diets, there are also indications that food skills are unlikely to ameliorate food insecurity on their own, particularly among groups suffering severe financial deprivation, isolation, and lack of accessibility to food. ${ }^{10,13,19,20-22}$

In Norway, a recent study has indicated that a high proportion of asylum seekers living in asylum reception centers are food insecure. $^{4,23}$ The tight budget asylum seekers receive from public authorities while waiting for their applications to be processed has emerged as the main cause of food insecurity and poor diet. ${ }^{4}$ Qualitative interviews also provided indications that the capability of cooking meals could also contribute to food insecurity and poor diets. ${ }^{23,24}$

Given the growing importance of nutrition education interventions to promote adequate diets among asylum seekers, this study aims to investigate the potential impact of food skills on food security and dietary diversity. ${ }^{12,25,26}$ Based on an investigation among asylum seekers living in Norwegian reception centers, the study wanted to assess whether asylum seekers with higher food skills were more likely to be food secure and have better diets (ie, a higher dietary diversity score). Findings from this study can be relevant for designing interventions promoting food security in this vulnerable population.

\section{METHODS}

This article is part of a larger study on food security and dietary diversity in asylum reception centers. ${ }^{4,23}$ The study was a cross-sectional survey among asylum seekers living in 8 Norwegian ordinary reception centers, which are facilities where asylum seekers can live while waiting for their asylum requests to be processed. $^{24}$ The Norwegian Directorate of Immigration has the formal responsibility for the centers, and the facilities are run by municipalities, private actors, or nonprofit organizations. $^{27}$ These facilities consist of both already existing buildings (such as old hospitals or hospices) or apartments shared by families or groups of individuals. In the case of buildings, kitchens are often located on one floor or in the main building and are generally characterized by having poor equipment such as a lack of tables, storage places, and old stoves. ${ }^{28}$ Kitchen facilities in apartments are also characterized by low standards. Buildings are more often located in rural areas, whereas apartments are located in urban areas. ${ }^{28}$ The study began in January 2017, when there were 11,438 registered asylum seekers. The study took place in the southern part of Norway, where approximately 2,100 asylum seekers were located. Ten ordinary reception centers in the southern region of Norway were selected because of variation in the location of the center (urban-rural) and the organization running the center (public, private, or nongovernmental organization). An informative e-mail about the purpose of the study was sent to those responsible for the centers, followed by a phone call by the party responsible for the project. Eight centers answered positively. After the approval, the research managers and fieldworkers visited the reception centers and informed residents about the project during their weekly meetings.

Participants were recruited through convenience sampling, aiming to include asylum seekers from the most common countries as well as participants of both genders. The participants consisted of adult men and women, and only 1 participant per family was selected to participate. Fieldworkers speaking the most common languages of the residents in the asylum centers (ie, Arabic, Somali, Dari, and Tigrinya, in addition to Norwegian and English) were employed for the project. In total, 205 asylum seekers (26\% of the asylum seekers registered as residents in the visited reception centers) answered questions from the interview-based questionnaires. The data collection was performed from January 31, 2017, to August 25, 2017; however, no data were collected during Ramadan (June), because of possible fasting.

\section{Questionnaire}

The questionnaire consisted of 4 parts: a 12-question module on demographic information and socioeconomic status, a 24-h dietary recall, a 19-question module on food skills, and a 10-question food security assessment. Food security was measured by the 10-item version of the Radimer/Cornell Hunger and Food Insecurity Scale and is discussed elsewhere. ${ }^{4,29}$ The 24 -h recall was used to calculate a dietary diversity score (DDS) to assess dietary quality according to the Food and Agriculture Organization guidelines for assessing dietary diversity among women. ${ }^{23}$ Eating from fewer than 5 of 10 food groups was defined as low dietary quality. ${ }^{23}$

Food skills were measured by adopting questions from the Canadian Community Health Survey 2013 Rapid Response on Food Skills, which is a validated questionnaire. ${ }^{30}$ The number of questions was reduced in consideration of the overall length of the questionnaire (ie, detailed questions related to skills in chopping or canning were not included). Furthermore, some questions were slightly simplified after pretest (ie, a question asking about the selection of foods based on food nutrition labels was changed into the selection of food considering its sugar or fat content, as the concept of nutrition labels was difficult to understand for some informants). The process of translating the questionnaire was done in close collaboration with the fieldworkers. One of them was of Somali origin, had spent part of their life in Arabic countries, and spoke fluent Somali, Arabic, English, and Norwegian. The other fieldworkers were fluent in English and/or Norwegian, in addition to their mother tongue. The translations were also reviewed by colleagues from countries included in the study. Fieldworkers received training in interview techniques from the project managers, who also conducted face-to-face testing of the questionnaires with a small sample of respondents to detect possible misunderstandings in the interpretation of the questions. The questionnaire was conducted as an in-person interview, which provided the opportunity to clarify questions. 


\section{Statistics}

Data were analyzed using SPSS (version 23.0, IBM Corporation, Armonk, NY, 2015) and Stata (version 14.1, StataCorp, College Station, TX, 2015). Tests were 2 -sided, and results were considered significant at the 0.05 level. Following the conceptualization of food skills found in the literature, food skills were divided into cooking skills (ability to prepare meals), and shopping skills (ability to plan meals, budget, and read labels). ${ }^{28}$ Cooking skills were measured using the following 3 questions: (1) How would you describe your ability to cook from basic ingredients? (2) How would you rate your skills in cooking a piece of raw meat, chicken, or fish? (3) How would you rate your skills in cooking a soup, stew, or casserole from scratch? Respondents could answer very good, good, basic, and very limited. These variables were recorded as binary, coding very good and good as high, and basic and very limited as low. The final variable, cooking, was coded as high cooking skills for those who had scored high on all the 3 questions (total score 3 ) and low cooking skills corresponding to all others (score 0-2). Shopping skills were measured using the following 5 questions. (1) When shopping for groceries, do you have a budget for how much you can spend? (2) Do you use a grocery list? (3) Do you plan meals before going to the store? (4) Do you compare prices? (5) Do you look at the content of sugar or fat? Possible answers were yes, sometimes, or no. The variables were recoded as binary, giving a score of 1 to yes, and a score of 0 to no or sometimes. The variable shopping skills was defined as high when respondents scored 4 or 5 , and low or moderate if they scored 3 or lower.

To determine which characteristics predicted higher cooking skills and which predicted higher shopping skills, different characteristics were tested in separate bivariate logistic regression models with the skill as the dependent variable. Predictors associated with the skill were then included in a multivariable model to assess whether associations remained. Multivariable models were assessed for multicollinearity using variance inflation factors. Characteristics tested included participant age, sex (male as reference category), marital status (unmarried or other, combined as reference category), education (higher education as reference category), previous employment (previously unemployed as reference category), and number of children.

To assess whether cooking and shopping skills were associated with improved dietary quality, separate bivariate logistic models were constructed testing whether the skill predicted adult food insecurity with hunger and if the skill predicted adequate dietary diversity. Finally, multivariable models were run testing whether the skill predicted dietary quality responses while controlling for participant age, sex, marital status, education, and number of children.

All informants received written and oral information about the study and were assured that the study had no implications for their application status. All informants gave written or oral consent to participate. The study was conducted according to the guidelines in the Declaration of Helsinki and ethical guidelines for research at Oslo Metropolitan University. The study was approved by the Norwegian Centre for Research Data (no. 50726).

\section{RESULTS}

The mean age of the participants was 31 years, and $36 \%$ were female (Table 1). The participants came from Syria (25\%), Eritrea (18\%), Somalia $(11 \%)$, Iraq $(11 \%)$, and other countries $(35 \%)$. The mean duration of stay in Norway was 29 months (range, 1-168). About 30\% were waiting for their application to be processed, 40\% had their application granted and were waiting to be relocated in a municipality, and $30 \%$ had their application rejected and were waiting for appeal. Of the asylum seekers, 93\% were categorized as food insecure; among these, $11 \%$ were food insecure without hunger, and $83 \%$ were food insecure with hunger. The mean (SD) DDS was 4.0 (1.6), and $60 \%$ of participants had low DDS (eating from fewer than 5 food groups).

The mean of cooking skills was 1.9 (range, 0-3), with $17 \%$ of the sample having no cooking skills at all, and 44\% having high cooking skills (Table 2). The mean for shopping skills was 2.7 (range, 0-5). In the sample, $4 \%$ had no shopping skills at all, whereas $7.8 \%$ had the highest shopping skills score (Table 2).

Participant age, sex, marital status, education, and number of children were associated with higher cooking skills in bivariate models (Table 3). In the multivariable model, including all these characteristics, participant age and sex remained significant with an adjusted odds ratio (OR) estimates similar in magnitude to the estimated bivariate OR. Marital status became marginally significant, and education and number of children were no longer associated with cooking skills. Of the measured characteristics, participant age and sex were strongly and consistently associated with cooking skills. Marital status, education, and number of children were also associated with cooking skills in bivariate models but not in the multivariable model. Only marital status was associated with improved shopping skills, and so no multivariable model was necessary (Table 4).

In bivariate models, cooking skills were associated with lower probability of adult food insecurity (OR, 0.38; 95\%, confidence interval [CI], 0.19-0.76) and a higher probability of adequate dietary diversity (OR, 2.50; 95\% CI, 1.41-4.43]) (Table 5). After controlling for participant characteristics, cooking skills were found to be still predictive of adequate dietary diversity (OR, 2.12; 95\% CI, 1.04-4.31]), but not of adult food insecurity (OR, 0.63; 95\% CI, 0.26-1.53). Higher shopping skills were not associated with either measure of dietary diversity or adult food insecurity.

\section{DISCUSSION}

This study aimed to investigate food skills among refugees living in Norwegian reception centers and their potential impact on food security and dietary diversity. The findings 


\section{Table 1. Background Characteristics of the Asylum Seekers $(n=205)$}

\section{Characteristics}

Age, y

Sex

Female

Male

Country of origin

Eritrea

Iraq

Somalia

Syria

Other

Marital status

Married

Single

Other

Living situation

Alone

Husband/wife without children

With children

With other not family

Asylum application status

Submitted

Granted

Rejected

Monthly budget, \$ (US) ${ }^{a}$

Months of stay in Norway

Food insecure

Low DDS ${ }^{b}$

\section{DDS indicates dietary diversity score.}

aSelf-report total monthly budget per person, the amount includes allowance for each person in addition to income from other sources; ${ }^{b} \mathrm{~A} 24-\mathrm{h}$ dietary recall was used to calculate the DDS, eating from fewer than 5 of 10 food groups was defined as low dietary quality. suggest that cooking skills and shopping skills contribute differently to food security and dietary diversity. Higher cooking skills were associated with higher dietary diversity but were not associated with food security. Shopping skills were not associated with either food security or dietary diversity. Women had higher cooking skills than men, but there were no gender differences in n (\%) or Mean \pm SD

$31.0 \pm 10.2$

$74(36.0)$

$131(64.0)$

36 (17.6)

$22(10.7)$

$22(10.7)$

$52(25.4)$

$72(35.1)$

79 (38.5)

95 (46.3)

$31(15.1)$

40 (19.5)

5 (2.4)

$44(21.5)$

$116(56.6)$

$63(30.7)$

$81(39.5)$

61 (29.8)

$320.0 \pm 193.0$

$28.8 \pm 30.9$

$190(92.7)$

$150(60.0)$ were used in this study, women had higher cooking skills than their Canadian counterparts. ${ }^{30}$ However, there is no consensus on how to define "low" or "high" food skills. ${ }^{15,31}$ Previous studies have indicated that these skills have to be considered as contextual and varying according to sociodemographic variables. ${ }^{16,17}$

An important finding of this study is that cooking skills contributed to dietary diversity. As other studies have shown, the possession of adequate cooking skills enables the preparation of meals with few resources and, therefore, represents an asset when budgets are limited. ${ }^{32-34}$ In this regard, the data from this study showed that women appear to have a slight advantage over men. This finding is not surprising because women have traditionally been the main providers of family meals. ${ }^{35,36}$ In Western societies, despite increasing equality in labor division in family tasks, women still do most of the cooking. ${ }^{36}$ Asylum seekers living in Norwegian reception centers tend to come from societies characterized by a strong division of gender roles, such as the Middle East and Sub-Saharan countries. In most of these countries, cooking for the family is typically a woman's task that girls learn from childhood. ${ }^{37,38}$

Cooking skills have been regarded as a form of embodied cultural capital involving mobilization of the mind/body within an environment offering different possibilities. ${ }^{39}$ Several studies investigating cooking practices among migrant women have shown that they bring with them the memory of gestures and tastes they have observed, experienced, and performed themselves in their home country. ${ }^{38,39}$ Referring to the data presented in this study,

\section{Table 2. Shopping Skills Among the Asylum Seekers $(n=205)$}

\begin{tabular}{lcr} 
Skill Level & Cooking Skills & Shopping Skills \\
No skills & $28(17.6)$ & $9(4.4)$ \\
Low & $28(14.6)$ & $28(13.7)$ \\
Medium & $49(23.9)$ & $105(51.2)$ \\
High & $90(43.9)$ & $63(30.7)$ \\
Total & $205(100.0)$ & $205(30.7)$ \\
\hline
\end{tabular}

Note: Values are $n(\%)$. Scores attribution: no skills = ; low skills = 1 ; cooking, medium skills = 2; shopping, medium skills $=2$ or 3 ; cooking, high skills $=3$; shopping, high skills $=4$ or 5 . 
Table 3. Logistic Regression Model of Cooking Skills Among the Asylum Seekers by Background Characteristics $(n=205)$

\begin{tabular}{|c|c|c|c|c|}
\hline Variable & Unadjusted OR (95\% Cl) & $\boldsymbol{P}$ & Adjusted OR $(95 \% \mathrm{Cl})$ & $\boldsymbol{P}$ \\
\hline Age & $1.07(1.03-1.10)$ & $<0.001$ & $1.07(1.02-1.12)$ & 0.003 \\
\hline Female & $9.96(5.09-19.46)$ & $<0.001$ & $9.00(4.33-18.71)$ & $<0.001$ \\
\hline Married & $2.84(1.59-5.07)$ & $<0.001$ & $1.99(0.93-4.24)$ & 0.07 \\
\hline Education & & 0.02 & & 0.18 \\
\hline Higher education & Referent & & Referent & \\
\hline Primary/secondary & $1.51(0.80-2.87)$ & & $2.02(0.92-4.42)$ & \\
\hline No education & $3.13(1.39-7.05)$ & 0.11 & $2.05(0.70-5.97)$ & \\
\hline Previously employed & $1.64(0.90-3.00)$ & 0.11 & - & \\
\hline Number of children & $1.44(1.15-1.81)$ & 0.002 & $0.94(0.70-1.28)$ & 0.70 \\
\hline
\end{tabular}

$\mathrm{Cl}$ indicates confidence interval; OR, odds ratio.

Note: Cooking skills were measured using 3 questions in which the respondents could answer very good, good, basic, or very limited. These variables were recorded as binary; coding very good and good as high, and basic and very limited as low cooking skills. The final variable, cooking, was coded as high cooking skills for those who had scored high on all the 3 questions (total score 3 ) and low cooking skills corresponding to all others (score 0 to 2 ).

cooking skills appear, therefore, to be a cultural capital that has the potential of being transferred and reproduced in different situations. ${ }^{40}$

However, it is important to be cautious in concluding that cooking skills alone can prevent food insecurity. As the data showed, high cooking skills have no significant effect on food security. Similar findings emerged from other studies indicating that in situations characterized by a paucity of resources, the contribution of cooking skills became less relevant as people with high cooking skills may still not be able to buy food or may lack the proper equipment to prepare food..$^{20,41,42}$ A previous publication

Table 4. Logistic Regression Model of Shopping Skills Among the Asylum Seekers by Background Characteristics $(n=205)$

\begin{tabular}{lcc} 
Variable & Unadjusted OR (95\% Cl) & $\boldsymbol{P}$ \\
Age & $1.01(0.99-1.04)$ & 0.34 \\
Female & $1.52(0.82-2.79)$ & 0.18 \\
Married & $2.30(1.25-4.21)$ & 0.007 \\
Education & & 0.36 \\
$\quad$ Higher education & Referent & \\
Primary/secondary & $0.66(0.34-1.28)$ & 0.14 \\
$\quad$ No education & $0.60(0.25-1.42)$ & 0.23 \\
Previously employed & $0.63(0.34-1.17)$ & \\
Number of children & $1.13(0.92-1.39)$ & \\
\hline
\end{tabular}

$\mathrm{Cl}$ indicates confidence interval; OR, odds ratio.

Note: Shopping skills were measured using 5 questions in which the respondents could answer yes, sometimes, or no. The variables were recoded as binary; giving score 1 to yes, and score 0 to no or sometimes. The variable shopping skills was defined as high when respondents scored 4 or 5 , and low or moderate if they scored 3 or lower.

Table 5. Logistic Regression Model by Cooking and Shopping Skills-Adult Food Insecurity and Dietary Diversity $(n=205)$

\begin{tabular}{lclll} 
Variable & Unadjusted OR $\mathbf{( 9 5 \%} \mathbf{~ C l )}$ & $\boldsymbol{P}$ & Adjusted $\left.\mathbf{O R}^{\mathbf{a}} \mathbf{( 9 5 \%} \mathbf{~ C l}\right)$ & $\boldsymbol{P}$ \\
$\begin{array}{l}\text { Adult food insecurity } \\
\quad \text { Cooking skills }\end{array}$ & $0.38(0.19-0.76)$ & 0.006 & $0.63(0.26-1.53)$ & 0.31 \\
$\quad$ Shopping skills & $0.66(0.33-1.33)$ & 0.25 & $0.79(0.35-1.78)$ & 0.58 \\
Adequate dietary diversity & & & & \\
$\quad$ Cooking skills & $2.50(1.41-4.43)$ & 0.002 & $2.12(1.04-4.31)$ & 0.04 \\
$\quad$ Shopping skills & $1.19(0.65-2.17)$ & 0.58 & $0.90(0.47-1.71)$ & 0.74 \\
\hline
\end{tabular}

$\mathrm{Cl}$ indicates confidence interval; OR, odds ratio.

${ }^{a}$ Adjusted for participant age, sex, marital status, and educational level. The reference categories for shopping and cooking skills as predictors is low skills. 
from the same study indicated that toward the end of the month, when money started to run out, the quality and the quantity of the food purchased tended to decrease despite cooking abilities. ${ }^{24}$ Poor kitchen conditions can as well represent a barrier to cooking and thus limit the use of cooking skills. ${ }^{43}$

This study did not find an association between shopping skills and food insecurity. This result contrasts with other studies that have indicated that confidence in planning, management, and selection of food can contribute to food security. ${ }^{20,44}$ A possible explanation could be that the adverse economic conditions experienced by the asylum seekers limit their opportunities to use their capacity for planning and budgeting. In fact, planning and budgeting for food imply the opportunity to manage a certain amount of economic resources, which may not be the case on the tight budgets of asylum seekers. ${ }^{20,45}$ As other studies have indicated, families with low income use several purchasing strategies, such as searching different shops to get the best bargains. ${ }^{32-34,46,47}$ Costs related to transport and distance from shops may limit this opportunity among asylum seekers. $^{24}$

Other complementary explanations of why shopping skills do not influence food security and dietary diversity are also possible. Food purchasing skills, for instance, can be less transferable and reusable than cooking skills. For example, language barriers and lack of availability of familiar products can challenge the use of previous knowledge in a new food environment. ${ }^{48,49}$ Moreover, purchasing skills that asylum seekers have acquired in their home countries may be less usable in a new food environment. In fact, the definition of food skills developed in the literature, and adopted in this study, are constructed around food purchasing skills typical of Western societies, which is mainly based on the assumption of consumption as an individualistic, rational behavior taking place in large retail stores. ${ }^{31,50}$ In this context, it is important to develop skills such as making lists, comparing prices, and reading labels, in order to make informed consumer choices. Although the development of this kind of consumer society in non-Western countries is increasing, the modernization of the retail system remains uneven geographically in terms of the products and the social class of consumers using supermarket outlets. ${ }^{51,52}$ In most of asylum seekers' home countries, shopping for food still tends to take place in local markets. ${ }^{53,54}$ In this context, the shopping skills needed implies being able to recognize the quality of products by smell and taste, being flexible in order to adapt food purchase to seasonal offerings, and being able to negotiate a good price. ${ }^{50}$ Shopping for food tends to be characterized by local contact with the retailer and is usually part of everyday social activity. As indicated by previous studies, this traditional commerce persists because it fulfills, beyond its economic function, a quasinatural task of the social bond. ${ }^{51}$ The importance of local markets as an arena for social bonds has been highlighted in studies investigating immigrant communities. ${ }^{5-58}$ In addition, low-income consumers in developing countries tend to place a great deal of emphasis on personal relationships with their retailers, and personal contact with shop owners can also lead to getting food on credit when there is a money shortage. ${ }^{57}$

The previously mentioned characteristics of food purchasing are not found in Norway, that is characterized by supermarket chains, global sourcing that diminishes seasonal variation, limited offerings of fresh produce, fixed prices, and impersonal and formal relations with supermarket employees. ${ }^{59}$ Moreover, open markets are almost nonexistent in Norway, and ethnic shops are mainly available in larger cities. Therefore, it may be the case that the purchasing skills that asylum seekers have acquired in their country of origin are less transferable in the new conditions. The fact that there was no significant variation according to gender may strengthen the interpretation that cooking skills and purchasing skills have to be considered separately. It also has to be considered that in societies characterized by segregation between gender roles, as the ones many women from this study come from, that shopping for food is an activity that women seldom do alone, as it is more appropriate to be accompanied by their husbands or other male relatives. ${ }^{54}$

As previous studies have pointed out, food insecurity can be seen as the concomitant scarcity of economic, cultural, and relational resources, lack of money to buy food, poor cooking skills, availability of food, and weak social networks that can provide support in case of need. ${ }^{60}$ Asylum seekers living in Norwegian reception centers seem to be suffering from overlapping scarcity of those opportunities and capabilities. $^{28,61}$ They suffer economic hardship as the money they are provided is hardly enough to meet their needs. ${ }^{61}$ At the time of this study, asylum seekers living in reception centers received approximately $\$ 280$ (USD)/mo per adult person, which had to cover all their expenses (ie, clothing, health fees, and transport, in addition to food). A Norwegian study indicates that, on average, a person would need that amount of money just to buy food. ${ }^{62}$ The cultural capital of asylum seekers also tends to be lower in the new country because, despite previous formal education, they have to cope with a new language, a new environment, and different norms and expectations. In this new context, previous knowledge about food may become illsuited, which may be the case with food purchasing skills. ${ }^{49}$ Finally, asylum seekers seem to suffer from weak social capital. ${ }^{63}$ Weak social networks, a condition that is likely to be experienced by immigrants upon resettlement, can be aggravated by the living conditions in asylum reception centers, which are characterized by isolation from the rest of society. ${ }^{64}$ The paucity of all these 3 forms of capital may explain the particularly high rate of food insecurity among asylum seekers in the reception centers. Initiatives aimed at promoting food security and dietary diversity among this vulnerable population need to address all of these aspects. Recent interventions based on food gardens, community kitchens, and food trucks have indicated positive results regarding food security because they address different causes of food insecurity, such as availability, accessibility, price, food 
skills, and using or activating social networks among refugees, and between refugees and local communities. $^{65-67}$

The primary strengths of this study are the relatively high number of participants compared with similar studies and the inclusion of men and women from different countries of origin. The interviews were conducted by fieldworkers speaking the language of the respondents, which increased the accuracy of the data collected. The study also has some limitations. First, the convenience sampling method used to recruit participants prevents generalization of the findings to all asylum seekers in Norway and introduces the possibility of selection bias. However, the gender distribution in this study represented the general gender distribution of asylum seekers in Norway in 2017, and participants from all the main countries of origin were included. Second, as food skills were self-reported, they may reflect individual perceptions and may not be an objective measure. ${ }^{18,31}$ The observation conducted during the fieldwork and the conversations with the respondents provided important elements for contextualizing the data from the study. A final limitation is that the back translation method has not been applied when translating the questionnaire from English to Norwegian or the other languages used in the study. The use for the translation and interviews of fieldworkers able to use several of the languages of the study may have helped to overcome this limitation partially.

\section{IMPLICATIONS FOR RESEARCH AND PRACTICE}

This study provides novel information on food skills and food security among asylum seekers. The findings from this study can be relevant for promoting initiatives ameliorating the nutrition situation among this vulnerable group. Food skills had a limited impact on food security and dietary diversity. Only cooking skills were associated with dietary diversity, suggesting the importance of initiatives promoting cooking skills among those with limited knowledge on meal preparation. The lack of association between shopping skills and food security and dietary diversity may suggest difficulties in shopping for food in an unfamiliar environment. Initiatives facilitating shopping for food in a new environment may be appropriate. These can include promoting competences in purchasing for food in supermarkets (eg, information about healthy food on a budget, discount campaigns, loyalty cards) and supporting access to affordable familiar food by providing transport to ethnic shops or organizing food distribution at the centers. Further research is also needed to identify food skills that asylum seekers adopted in their country of origin, and that could be useful during resettlement. Finally, the study indicated that also among those having high cooking and shopping skills, the level of food insecurity remained high, which suggests that initiatives addressing the multiple causes of food insecurity are warranted.

\section{ACKNOWLEDGMENTS}

The present study was funded by research funds of the Public Health Nutrition Research Group at Oslo Metropolitan University, the Healthy Start at Asylum Reception Centers project promoted by the Multicultural Center of Oslo and Akershus, and the Directorate of Integration and Diversity. The funders had no role in study design, data collection and analysis, decision to publish, or preparation of the manuscript. The authors thank all the participants for their cooperation, as well as Dawid Mauno, Khadra M. Omar, Eden Kassie, and Mahshid Razmi for assisting with the data collection.

\section{REFERENCES}

1. McKay FH, Dunn M. Food security among asylum seekers in Melbourne. Aust N Z J Public Health. 2015;39:344349.

2. Dharod JM, Croom J, Sady CG, Morrell D. Dietary intake, food security, and acculturation among Somali refugees in the United States: results of a pilot study. J Immigr Refugee Stud. 2011;9:82-97.
3. Hadley C, Sellen D. Food security and child hunger among recently resettled Liberian refugees and asylum seekers: a pilot study. J Immigr Minor Health. 2006;8:369-375.

4. Henjum S, Morseth MS, Arnold CD, Mauno D, Terragni L. "I worry if I will have food tomorrow": a study on food insecurity among asylum seekers living in Norway. BMC Public Health. 2019;19:592.

5. Borch A, Kjaernes U. Food security and food insecurity in Europe: an analysis of the academic discourse (1975 -2013). Appetite. 2016;103:137-147.

6. Gorton D, Bullen CR, Mhurchu CN. Environmental influences on food security in high-income countries. Nutr Rev. 2010;68:1-29.

7. Burchi F, De Muro P. From food availability to nutritional capabilities: advancing food security analysis. Food Policy. 2016;60:10-19.

8. Sen A. Development: which way now? Econ J. 1983;93:745-762.

9. Sen A. Commodities and Capabilities. Oxford, England: Oxford University Press; 1999.

10. Dollahite J, Olson C, Scott-Pierce C. The impact of nutrition education on food insecurity among low-income participants in EFNEP. Fam Con Sci Res J. 2003;32:127-139.

11. Wrieden WL, Anderson AS, Longbottom PJ, et al. The impact of a community-based food skills intervention on cooking confidence, food preparation methods and dietary choices - an exploratory trial. Public Health Nutr. 2007;10:203-211.

12. Gunnell S, Christensen NK, Jewkes MD, LeBlanc H, Christofferson D. Providing nutrition education to recently resettled refugees: piloting a collaborative model and evaluation methods. J Immigr Minor Health. 2015;17:482-488.

13. Pooler JA, Morgan RE, Wong K, Wilkin MK, Blitstein JL. Cooking matters for adults improves food resource management skills and self-confidence among low-income participants. J Nutr Educ Behav. 2017;49:545-553. e1

14. Jetter KM, Adkins J, Cortez S, Hopper GK Jr, Shively V, Styne DM. Yes we can: eating healthy on a limited budget. J Nutr Educ Behav. 2019;51:268-276.

15. McGowan L, Caraher M, Raats M, et al. Domestic cooking and food skills: a review. Crit Rev Food Sci Nutr. 2017;57:2412-2431. 
16. Vidgen HA, Gallegos D. Defining food literacy and its components. Appetite. 2014; 76:50-59.

17. Perry EA, Thomas H, Samra HR, et al. Identifying attributes of food literacy: a scoping review. Public Health Nutr. 2017;20:2406-2415.

18. Kennedy LG, Kichler EJ, Seabrook JA, Matthews JI, Dworatzek PDN. Validity and reliability of a food skills questionnaire. J Nutr Educ Behav. 2019;51:857864.

19. Dewolfe JA, Greaves G. The Basic Shelf Experience: a comprehensive evaluation. Can J Diet Pract Res. 2003;64:51-57.

20. Begley A, Paynter E, Butcher LM, Dhaliwal SS. Examining the association between food literacy and food insecurity. Nutrients. 2019;11:445

21. Huisken A, Orr SK, Tarasuk V. Adults' food skills and use of gardens are not associated with household food insecurity in Canada. Can J Public Health. 2017;107:e526-e532.

22. Palumbo R, Adinolfi P, Annarumma C, et al. Unravelling the food literacy puzzle: evidence from Italy. Food Policy. 2019;83:104-115.

23. Henjum S, Caswell BL, Terragni L. "I feel like I'm eating rice 24 hours a day, 7 days a week": dietary diversity among asylum seekers living in Norway. $\mathrm{Nu}$ trients. 2019;11:2293.

24. Terragni L, Henjum S, Barbala I, et al. "Meagre hospitality". Experiences with food among asylum seekers living in Norwegian reception centres. Anthropol Food. 2018;S12:9129.

25. Terragni L, Garnweidner-Holme L, Næss TV, Hussain A, Eriksen AM. A healthy start: development of nutrition education for newly resettled immigrants and refugees living in Norway. Int J Home Econ. 2018; 11:80-91.

26. Nunnery DL, Haldeman LA, Morrison SD, Dharod JM. Food insecurity and budgeting among Liberians in the US: how are they related to sociodemographic and pre-resettlement characteristics. J Immigr Minor Health. 2015; 17:506-512.

27. Valenta M, Berg B, eds. Asylsøker - i velferdsstatens venterom, Oslo, Norway: Universitetsforlaget; 2012.

28. Hauge ÅL, Støa E, Denizou K. Framing outsidedness - aspects of housing quality in decentralized reception centres for asylum seekers in Norway. Hous Theor Soc. 2017;34:1-20.
29. Sellen DW, Tedstone AE, Frize J. Food insecurity among refugee families in East London: results of a pilot assessment. Public Health Nutr. 2002;5:637-644.

30. Slater JJ, Mudryj AN. Self-perceived eating habits and food skills of Canadians. J Nutr Educ Behav. 2016;48: 486-495. e1.

31. Lavelle F, McGowan L, Hollywood L, et al. The development and validation of measures to assess cooking skills and food skills. Int $J$ Behav Nutr Phys Act. 2017;14:118

32. Power M, Small N, Doherty B, Pickett KE. Hidden hunger? Experiences of food insecurity amongst Pakistani and white British women. $\mathrm{Br}$ Food $\mathrm{J}$. 2018;120:2716-2732.

33. Daly M, Kelly G. Families and Poverty: Everyday Life on a Low Income. Bristol, United Kingdom: Policy Press; 2015.

34. Hammelman C. Urban migrant women's everyday food insecurity coping strategies foster alternative urban imaginaries of a more democratic food system. Urban Geogr. 2018;39:706-725.

35. DeVault ML. Feeding the Family: The Social Organization of Caring as Gendered Work. Chicago, IL: The University of Chicago Press; 1991.

36. Holm L, Ekström MP, Hach S, Lund TB. Cooking and gender. In: Gronow J, Holm L, eds. Everyday Eating in Denmark, Finland, Norway and Sweden: A Comparative Study of Meal Patterns 1997-2012. London, United Kingdom: Bloomsbury Academic; 2019:123-140.

37. Abbots EJ. Approaches to food and migration: rootedness, being and belonging. In: Klein J, Watson J, eds. The Handbook of Food and Anthropology. London, United Kingdom: Bloomsbury Publishing; 2016:115-132.

38. Trubek AB. Looking at cooking. Anthropol Now. 2012;4:24-32.

39. Sutton D. Cooking skill, the senses, and memory: the fate of practical knowledge. In: Edwards E, Gosden C, Phillips R, eds. Sensible Objects: Colonialism, Museums and Material Culture. Oxford, United Kingdom: Berg Publishing; 2006:87-120.

40. Erel U. Migrating cultural capital: Bourdieu in migration studies. Sociology. 2010;44:642-660

41. Buck-McFadyen EV. Rural food insecurity: when cooking skills, homegrown food, and perseverance aren't enough to feed a family. Can J Public Health. 2015;106:e140-e146.
42. Mclaughlin C, Tarasuk V, Kreiger N. An examination of at-home food preparation activity among low-income, food-insecure women. J Am Diet Assoc. 2003;103:1506-1512.

43. Barbala IM, Grewal N, Haug H, Eriksen AM, Terragni L. Mat for fremtiden. Erfaringer med et matlagingskurs blant asylsøkere ved et integreringsmottak. Norsk Tidskrift for Ernoering. 2019;4:8-17.

44. Burge C, Dharod JM. What are the nutrition education needs of refugees: assessment of food choices, shopping and spending practices of South-Asian refugees in the USA. J Int Migr Integr. 2018;19:555-564.

45. Dachner N, Ricciuto L, Kirkpatrick SI, Tarasuk V. Food purchasing and food insecurity among low-income families in Toronto. Can J Diet Pract Res. 2010;71:e50-e56.

46. Weisberg-Shapiro P, Devine C. Food activity footprint: Dominican women's use of time and space for food procurement. J Hunger Environ Nutr. 2020;15: 683-698.

47. Nielsen A, Lund TB, Holm L. The taste of 'the end of the month', and how to avoid it: coping with restrained food budgets in a Scandinavian welfare state context. Soc Policy Soc. 2015;14:429-442.

48. Mannion CA, Raffin-Bouchal S, Henshaw CJ. Navigating a strange and complex environment: experiences of Sudanese refugee women using a new nutrition resource. Int J Womens Health. 2014;6:411-422.

49. Terragni L, Garnweidner LM, Pettersen KS, Mosdøl A. Migration as a turning point in food habits: the early phase of dietary acculturation among women from South Asian, African, and Middle Eastern countries living in Norway. Ecol Food Nutr. 2014;53:273-291.

50. Berg L. Competent consumers? Consumer competence profiles in Norway. Int J Con Stud. 2007;31:418-427.

51. Amine A, Lazzaoui N. Shoppers' reactions to modern food retailing systems in an emerging country. Int J Retail Distrib Manag. 2011;39:562-581.

52. Amine A, Tanfous FHB. Exploring consumers' opposition motives to the modern retailing format in the Tunisian market. Int $J$ Retail Distrib Manag. 2012;40:510-527

53. Godefroit-Winkel D. Developing shopping abilities to empower: an ethnography of Moroccan women in 
supermarkets. Mark Glob Dev Rev. 2018;3:2.

54. Sehib K, Jackson E, Gorton M. Gender, social acceptability and the adoption of supermarkets: evidence from Libya. Int $J$ Con Stud. 2013;37:379-386.

55. Black RE. The Porta Palazzo farmers' market: local food, regulations and changing traditions. Anthropol Food. 2005;4:157.

56. Gasparetti F. Eating tie bou jenn in Turin: negotiating differences and building community among Senegalese migrants in Italy. Food Foodways. 2012; 20:257-278.

57. Joassart-Marcelli P, Rossiter JS, Bosco FJ. Ethnic markets and community food security in an urban "food desert". Environ Plan A. 2017;49:1642-1663.

58. Tuomainen H. Ghanaian cuisine entering the cosmopolitan stage - the role

Journal of Nutrition Education and Behavior • Volume 52, Number 11, 2020

of women, meal formats, and menu adaptations in the shaping of Ghanaian restaurants in London. Anthropol Food. 2018;S12:9149.

59. Kjærnes U, Harvey M, Warde A. Trust in Food: A Comparative and Institutional Analysis. New York, NY: Palgrave Macmillan; 2007.

60. Nielsen A, Holm L. Making the most of less: food budget restraint in a Scandinavian welfare society. Food Cult Soc. 2016;19:71-91.

61. Seeberg ML, Bagge C, Enger TA. No place: small children in Norwegian asylum-seeker reception centres. Childhood. 2009;16:395-411.

62. Borgeraas E. Minimumsbudsjett for forbruksutgifter. Oslo, Norway: Høgskolen i Oslo og Akershus; 2016.

63. Engebrigtsen AI. Kinship, gender and adaptation processes in exile: the case of
Tamil and Somali families in Norway. J Ethn Migr Stud. 2007;33:727-746.

64. Jonzon R, Lindkvist P, Johansson E. A state of limbo-in transition between two contexts: health assessments upon arrival in Sweden as perceived by former Eritrean asylum seekers. Scand $J$ Public Health. 2015;43:548-558.

65. Edge S, Meyer SB. Pursuing dignified food security through novel collaborative governance initiatives: perceived benefits, tensions and lessons learned. Soc Sci Med. 2019;232:77-85.

66. Haines BC, McKay FH, Dunn M, Lippi $\mathrm{K}$. The role of social enterprise in food insecurity among asylum seekers. Health Soc Care Community. 2018;26:829-838.

67. McKay FH, Lippi K, Dunn M, Haines BC, Lindberg R. Food-based social enterprises and asylum seekers: the food justice truck. Nutrients. 2018;10:756. 